\title{
HLA-Cw6 status predicts efficacy of biologic treatments in psoriasis patients
}

\author{
Wayne P Gulliver ${ }^{1,2 *}$, Heather Young ${ }^{1}$, Susanne Gulliver ${ }^{1}$ and Shane Randell ${ }^{1,2}$ \\ ${ }^{1}$ Newlab Clinical Research, St. John's, NL, Canada \\ ${ }^{2}$ Department of Medicine, Faculty of Medicine, Memorial University of Newfoundland, St. John's, NL, Canada
}

\begin{abstract}
Over the past decade, biologic therapies have been developed to treat auto-inflammatory conditions such as psoriasis. They have the advantage of better target specificity than traditional systemics such as methotrexate and cyclosporine and therefore significantly reduce side-effects and toxicity associated with wide spread systemic treatments. It has been suggested that the efficacy of biologics used in the treatment of psoriasis may be related with HLA-Cw6 status.Using HLA-Cw6 as a biomarker would therefore provide an advantage in the selection of a biologic agent for successful treatment based on a patient's genetic makeup and thus allowing us to use HLA-Cw6 to individualize therapy for patients with moderate-to-severe psoriasis.In the present study, the HLA-Cw6 status was determined for psoriasis patients previously treated with etanercept, adalimumab, efalizumab, infliximab or ustekinumab. The success or failure rates of the biologic treatments were compared for patients with and without the HLA-Cw6 allele.The HLA-Cw6 status was significantly associated to the treatment outcomes for biologics efalizumab (no longer on the market), infliximab and ustekinumab; but not etanercept or adalimumab. These results support the use of HLA-Cw6 status as a biomarker for biologic treatment in moderate-to-severe psoriasis patients.
\end{abstract}

\section{Introduction}

Psoriasis vulgaris is a chronic inflammatory skin disease that presents as scaly plaques on the skin [1] and is estimated to affect 2-3\% of the population. While the specific etiology remains elusive, studies have suggested a mechanism stimulating inappropriate immunemediated and inflammatory responses. It is hypothesised that the antimicrobial peptide LL-37and HLA-Cw6 may play a role in the pathogenesis of psoriasis [2,3]. LL-37 is overexpressed in keratinocytes in psoriasis and via HLA-Cw6 is presented as the auto antigen to CD-8 positive (Tc1/17) cells and to dendritic cells leading to the production of cytokinestriggering an inflammatory cascade in psoriasis patients [2]. Psoriatic lesions are characterized by keratinocyte hyper-proliferation and inflammation resulting from $\mathrm{T}$-cell differentiation and abundance of pro-inflammatory cytokines such as interferon-gamma (IFNY), tumour necrosis factor alpha (TNFa), interleukin (IL) 12 and IL-23 $[1,4,5]$ and is mediated via LL-37 and HLA-Cw6 [2].

Psoriasis pathogenesis is multi-factorial, but includes a significant genetic component: first-degree relatives are 4-6 times more likely to develop psoriasis [5] and monozygotic twins are both affected more frequently than dizygotic twins [6]. Susceptibility studies have identified candidate genes in the PSORS1 region of chromosome 6 , most significantly the HLA-C gene in the region of the major histocompatibility complex (MHC) [7,8]. The HLA-C isotype HLA$C w 6$ is strongly associated with the development of psoriasis and with a more severe form presenting at a younger age [8-11].

The association of psoriasis with HLA was demonstrated in 1980 with the strongest association seen in the HLA-Cw6 allele [9]. Research from 1993 suggests that the HLA-Cw6 allele is an indicator for susceptibility for psoriasis development as well as early age of onset in HLA-Cw6 positive psoriasis patients [8]. Individuals with late onset of disease and are HLA-Cw6 positive tend to have milder severity [12].
The association appears strong and is found in anywhere from 40$80 \%$ of cases [9], however other genes nearby may play a role that also contribute to the development of psoriasis. There are other gene-disease associations that are documented indicating stronger causality such as HLA-B27 and ankylosing spondylitis (AS) where the HLA-B27 allele is seen in up to $100 \%$ of AS patients [13]. Even though the relationship between psoriasis and HLA-Cw6 may not be as definitive as HLA-B27 and $\mathrm{AS}$, the association has consistently been seen in psoriasis patients.

In the past decade, biologic therapies have been introduced and embraced as an ideal treatment option as they generally have high efficacy and a favourable benefit-to-risk ratio. New developments in the pharmacogenetics of psoriasis could help better predict the likelihood of response to biologic therapies in moderate to severe psoriasis patients using HLA-Cw6 as a marker [2].

\section{Materials and methods}

Psoriasis patients treated with one of five biologics were selected from the Newfoundland and Labrador founder population and grouped as being either responsive or non-responsive to biological treatment. Patients were then tested for the HLA-Cw6 single nucleotide polymorphism (SNP).

Blood samples were collected in sterile $10 \mathrm{~mL}$ tubes containing EDTA.Isolation and purification of DNA was performed using either Promega Wizard Genomic DNA Purification kit or AutoGen Mini80 QuickGene DNA Whole Blood Kit, as per the manufacturer's

Correspondence to: Dr. Wayne Gulliver, Newlab Clinical Research, 187 Lemarchant Road, St. John's, NL, Canada, A1C 2H5, Tel: 1-709-753-5520; E-mail: WGulliver@newlabresearch.com

Received: December 01, 2015; Accepted: December 16, 2015; Published: December 19, 2015 
instructions.Resulting DNA was diluted to $30 \mathrm{ng} / \mu \mathrm{L}$ for use in polymerase chain reaction (PCR).

PCR was performed using the Olerup SSP HLA-Cw06 amplification kit (Stockholm, Sweden), as per the manufactures instructions.A solution was created using DNA, sterile water, and master mix containing Taq polymerase, nucleotides, and divalent ions. The solution was mixed and $10 \mu \mathrm{L}$ aliquoted in to tubes containing dried primer pairs for both control and test sequences. Tubes were placed in the thermocycler and amplified for 10 cycles at $94^{\circ} \mathrm{C}$ for 10 seconds to denature and $65^{\circ} \mathrm{C}$ for 60 seconds to anneal and extend:for the last 20 cycles, DNA was amplified for 10 cycles at $94^{\circ} \mathrm{C}$ for 10 seconds to denature, $61^{\circ} \mathrm{C}$ for 50 seconds to anneal, $72^{\circ} \mathrm{C}$ for 30 seconds to extend, then held at $4^{\circ} \mathrm{C}$. Amplification products and a DNA ladder were loaded in to a $2 \%$ agarose gel made/run using $0.5 \mathrm{X}$ TE buffer at 8-10 volts/cm for 15-20 minutes. The gel was then transferred to a Bioimager, a picture taken under UV light, and genotype status recorded.

Genotype data was then used to further subgroup patients in the responsive and non-responsive groups as being HLA-Cw6+ or HLACw6-. Resulting data was put in a contingency table, the odds ratio calculated, and significance determined using Fisher's exact test for two-tailed samples. Separate contingency tables were also made for each of the biologics: etanercept, adalimumab, efalizumab, infliximab and ustekinumab.

\section{Results}

Figure 1 (Efficacy of Different Biologics on HLC-cw6 Positive and
Negative Psoriasis Patients) can be seen below. Figure la compares the efficacy of all biologics on patients with that are HLA-Cw6 positive or negative. Figures $1 \mathrm{~b}, 1 \mathrm{c}, 1 \mathrm{~d}, 1 \mathrm{e}$, and 1f compare the genotype status on efficacy for etanercept, adalimumab, efalizumab, infliximab and ustekinumab, respectively.

Biologics in general were found to be significantly more effective in patients that are HLA-Cw6 positive $(\mathrm{OR}=4.427, \mathrm{p}=0.0005)$. Of the five biologic treatments tested, infliximab, ustekinumab, and efalizumab demonstrated significant differences in efficacy between HLA-Cw6 positive and negative patients $(\mathrm{p}=0.0391, \mathrm{p}=0.0112$, and $\mathrm{p}=0.0124$, respectively): The efficacies of all three biologics were significantly higher in HLA-Cw6 patients $(\mathrm{OR}=8, \mathrm{OR}=21, \mathrm{OR}=23)$. There was no significance difference in symptom resolution between HLA-Cw6 positive and negative patients treated with etanercept or adalimumab ( $\mathrm{OR}=1, \mathrm{p}=1.0000 ; \mathrm{OR}=1.2, \mathrm{p}=1.0000$, respectively).

In order to increase the statistical power of analysis, our data was pooled with data from Talamonti et al., [14] and Costanzo et al., [15] for patients taking etanercept, ustekinumab, and efalizumab.Data was re-analyzed and is presented in Figure 2 (Efficacy of Etanercept, Ustekinumab, and Efalizumab on HLA-Cw6 Positive and Negative Psoriasis Patients). The efficacy of ustekinumab and efalizumab were again significantly higher in HLA-Cw6 positive patients ( $\mathrm{p}=0.0001$ and $\mathrm{p}=0.0101$ respectively). Etanercept demonstrated a non-significant trend of increased efficacy in HLA-Cw6 negative patients.
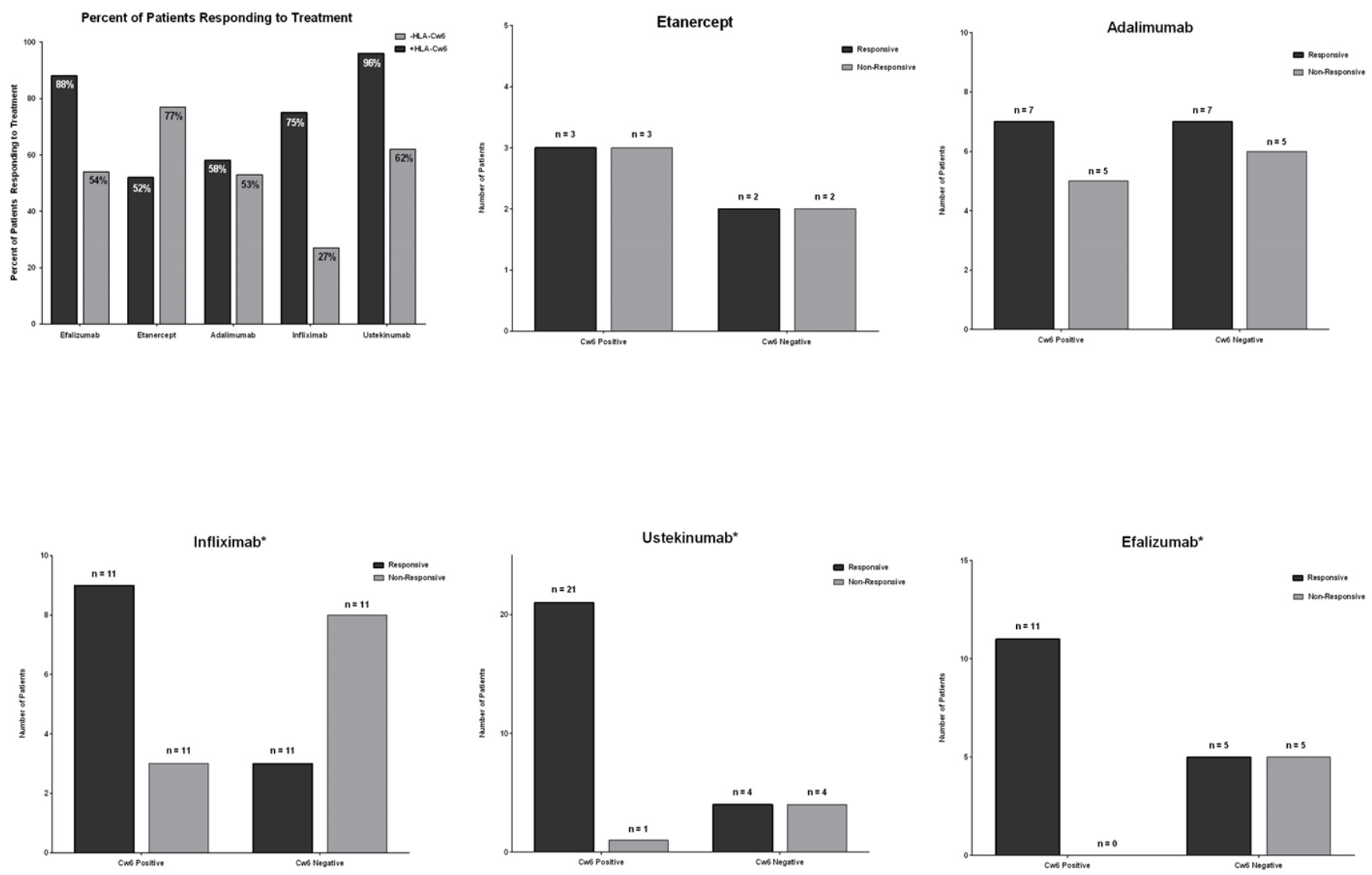

Figure 1. Efficacy of Different Biologics on HLC-cw6 Positive and Negative Psoriasis Patients. 

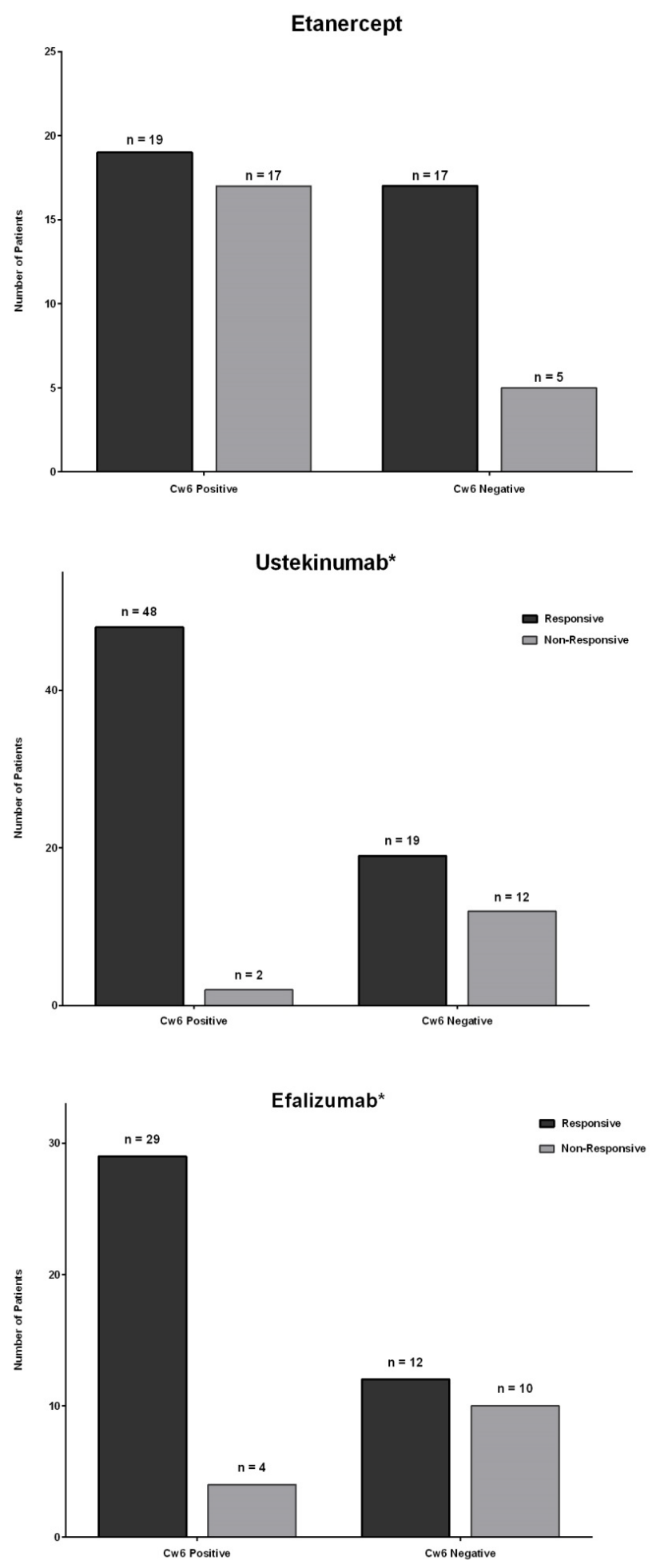

Figure 2. Efficacy of Etanercept, Ustekinumab, and Efalizumab on HLA-Cw6 Positive and Negative Psoriasis Patients.

\section{Discussion}

Psoriasis has been observed have bimodal peaks of age of onset; the first occurring around the age of 20 and the second occurring around the age of 50 [6]. In non-pustular psoriasis, two types can be independently observed; Type I and Type II. Type I psoriasis often encompasses positive family history, linkage disequilibrium for human leucocyte antigens (HLAs) Cw6, B13 and Bw57 as well as an early onset (the first peak) [6]. Type II presents around the second peak (age 5060) and tends to have higher with Cw2 and B27 [16]. Psoriasis has been linked to numerous comorbidities such as cardiovascular disease, diabetes, hypertension, obesity and dyslipidemia [17]. Associations with multiple traditional cardiovascular risk factors (such as smoking, obesity, stress and chronic inflammation) are documented and may lead to an increase in risk of mortality in patients admitted to the hospital at least once for their skin by $50 \%[18,19]$.

The association between psoriasis and HLA-Cw6 was first documented in the 1980s and since then this association has been observed consistently as having the highest association with psoriasis and representing the most obvious biomarker candidate $[8,20]$. Psoriasis has been difficult to map to a specific locus, likely due to the number of factors involved in dysregulation/inflammation and the multiple gene loci they represent [16]. The identification of other candidate genes likely represents a separate pathogenic pathway leading to psoriasis in the non-HLA-Cw6 patients. The HLA-Cw6 status has long been associated with early-onset psoriasis and severe symptoms $[8,21]$. Other studies have reported psoriasis associations with HLA-B and non-HLA genes (such as HCR and CDSN) within the MHC but independence from HLA-C has yet to be established. Still, HLA-C is well established as a psoriasis gene with HLA-Cw6 positivity leading to an increase in risk of developing psoriasis as part of an integrated complex involving skin barrier function signalling [20]. It is believed that HLA-Cw6 positivity is linked to an early age of onset of psoriasis and a paediatric study using an East Indian population [10] found that Guttate psoriasis, scalp involvement and severe disease all corresponded to HLA-Cw6 positivity in these children.In this study, we present new evidence to support the use of HLA-Cw6 status as a biomarker for biologic treatment selection. Traditionally, specific biologics were prescribed on a trial-and-error basis.Studies have also shown that PGA 0/1 response to a biologic that is used as a second line therapy is lower than when it is used as a first line therapy, making the treatment significantly less cost effective [22,23]. These results demonstrate the predictive value of HLA-Cw6 genotyping on the success of biologic treatments.Commercially available kits are already available for HLA-Cw6 genotyping and are significantly more cost effective than an unsuccessful round of biologic treatment and significantly reduce the unnecessary risk of a trial-and-error treatment approach.

\section{Conclusion}

HLA-Cw6 is believed to be a susceptibility gene for Psoriasis vulgaris. Biologic therapies are proving to be an effective treatment option with a favourable benefit-to-risk ratio. It has been rather difficult to choose which biologic therapy to use which is seen in the present treatment paradigm of the trial-and-error approach. However recent literature, as well as the data presented in this study, suggests that HLA-Cw6 positivity may be associated with increased efficacy in certain biologic therapies. Thus the approach using individualized medicine is likely to result in a multitude of benefits including: more timely control of the disease and timely improvements in quality of life and productivity; as well as less switching from one biologic therapy to another, and improvements in the cost effectiveness of biologic therapies for the treatment of moderate-to-severe psoriasis. 


\section{References}

1. Xu N, Meisgen F, Butler LM, Han G, Wang XJ et al. (2012) MicroRNA-31 is Overexpressed in Psoriasis and Modulates Inflammatory Cytokine and Chemokine Production in Keratinocytes via Targeting Serine/Threonine Kinase 40. J Immunol 190: 678-688. [Crossref]

2. Lande R, Botti E, Jandus C, Dojcinovic D, Fanelli G, et al. (2014) The antimicrobia peptide LL37 is a T-cell autoantigen in psoriasis. Nat Commun 5: 5621. [Crossref].

3. Costanzo A, Spallone G, Talamonti M, Botti E, Chimenti S (2010) New Developments in the Pharmacogenetics of Psoriasis: HLA-Cw6 as a Marker for the Treatment of Psoriasis with Biological Therapies. Adv Psor Inflamm Skin Dis 1: 125-130.

4. Ahlehoff O, Gislason GH, Lindhardsen J, Olesen JB, Charlot M, et al. (2011) Prognosis following first-time myocardial infarction in patients with psoriasis: a Danish nationwide cohort study. J Intern Med 270: 237-244.[Crossref]

5. Girolomoni G, Mrowietz U, Paul C (2012) Psoriasis: rationale for targeting interleukin-17. Br J Dermatol 167: 717-724.[Crossref]

6. Lønnberg AS, Skov L, Skytthe A, Kyvik KO, Pedersen OB, et al. (2013) Heritability of psoriasis in a large twin sample. Br J Dermatol 169: 412-416.[Crossref]

7. Clop A, Bertoni A, Spain S, Simpson M, Pullabhatla V, Tonda R, et al. (2013). An In-Depth Characterization of the Major Psoriasis Susceptibility Locus identifies Candidate Susceptibility Alleles within an HLA-C Enhancer Element. PLOS ONE 8: 1-8. [Crossref]

8. Gulliver W, Pirzada SM (2008) "Psoriasis; "more than skin deep". Recent Advances in Skin Immunology: 167-179.

9. Tiilikainen A, Lassus A, Karvonen J, Vartiainen P, Julin M (1980) Psoriasis and HLACw6. Br J Dermatol 102: 179-184. [Crossref]

10. Sathishkumar D, George R, Daniel D, Peter JV (2015) Clinical profile of childhoodonset psoriasis and prevalence of HLA-Cw6: a hospital-based study from India. Postgrad Med J 91: 309-314. [Crossref]

11. Baurecht H, Hotze M, Brand S, Büning C, Cormican P, et al. (2015) Genome-wide comparative analysis of atopic dermatitis and psoriasis gives insight into opposing genetic mechanisms. Am J Hum Genet 96: 104-120. [Crossref]

12. Bahcetepe N, Kutlubay Z, Yilmaz E, Tuzun Y, Eren B (2013) The role of HLA antigens in the aetiology of psoriasis. Med Glas (Zenica) 10: 339-342. [Crossref]
13. Oka A, Tamiya G, Tomizawa M (1999). Association analysis using refined microsatellite markers localizes a susceptibility locus for psoriasis vulgaris within 111 $\mathrm{kb}$ segment telomeric to the HLA-C gene. Hum Mol Genet 8: 2165-2170. [Crossref]

14. Talamonti M, Botti E, Galluzzo M, Teoli M, Spallone G, et al. (2013) Pharmacogenetics of psoriasis: HLA-Cw6 but not LCE3B/3C deletion nor TNFAIP3 polymorphism predisposes to clinical response to interleukin 12/23 blocker ustekinumab. $\mathrm{Br} J$ Dermatol 169: 458-463. [Crossref]

15. Costanzo A (2009) Cw0602 allele is a potential predictor of response to efalizumab treatment in psoriasis. JAAD 60: 3 .

16. Bowcock AM, Cookson WO (2004) The genetics of psoriasis, psoriatic arthritis and atopic dermatitis. Hum Mol Genet 13: R43-55. [Crossref]

17. Gulliver W (2008) Long-term prognosis in patients with psoriasis. Br J Dermatol 159 Suppl 2: 2-9. [Crossref]

18. Gulliver WP, Macdonald D, Gladney N, Alaghehbandan R, Rahman P, et al. (2011) Long-term prognosis and comorbidities associated with psoriasis in the Newfoundland and Labrador founder population. J Cutan Med Surg 15: 37-47. [Crossref]

19. Gulliver WP, Macdonald D, Gladney N, Alaghehbandan R, Rahman P, et al. (2011) Long-term prognosis and comorbidities associated with psoriasis in the Newfoundland and Labrador founder population. J Cutan Med Surg 15: 37-47. [Crossref]

20. Leman J, Burden A (2008) Treatment of severe psoriasis with infliximab. Ther Clin Risk Manag 4: 1165-1176. [Crossref]

21. Rahman P, Elder JT (2012) Genetics of psoriasis and psoriatic arthritis: a report from the GRAPPA 2010 annual meeting. J Rheumatol 39: 431-433. [Crossref]

22. Gudjónsson JE, Kárason A, Antonsdóttir AA, Rúnarsdóttir EH, Gulcher JR, et al (2002) HLA-Cw6-positive and HLA-Cw6-negative patients with Psoriasis vulgaris have distinct clinical features. J Invest Dermatol 118: 362-365. [Crossref]

23. Kundakçi N, Oskay T, Ölmez U, Tutkak H, Gürgey E (2002). Association of psoriasis vulgaris with HLA class I and class II antigens in the Turkish population, according to the age at onset. Int J Dermatol 41: 345-348. [Crossref]

24. Papp K, Bissonnette R, Krueger JG, Carey W, Gratton D, et al. (2001) The treatment of moderate to severe psoriasis with a new anti-CD11a monoclonal antibody. $J$ Am Acad Dermatol 45: 665-674.[Crossref]

Copyright: (C2015 Gulliver WP. This is an open-access article distributed under the terms of the Creative Commons Attribution License, which permits unrestricted use, distribution, and reproduction in any medium, provided the original author and source are credited. 